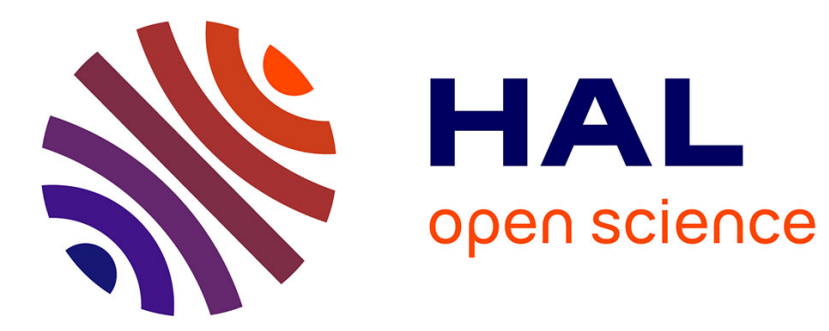

\title{
The impact of seabed rock roughness on tidal stream power extraction
}

\author{
Nicolas Guillou, Jérôme Thiebot
}

\section{To cite this version:}

Nicolas Guillou, Jérôme Thiebot. The impact of seabed rock roughness on tidal stream power extraction. Energy, 2016, 112, pp.762-773. 10.1016/j.energy.2016.06.053 . hal-01673396

\section{HAL Id: hal-01673396 https://hal.science/hal-01673396}

Submitted on 3 Jan 2018

HAL is a multi-disciplinary open access archive for the deposit and dissemination of scientific research documents, whether they are published or not. The documents may come from teaching and research institutions in France or abroad, or from public or private research centers.
L'archive ouverte pluridisciplinaire HAL, est destinée au dépôt et à la diffusion de documents scientifiques de niveau recherche, publiés ou non, émanant des établissements d'enseignement et de recherche français ou étrangers, des laboratoires publics ou privés. 


\title{
The impact of seabed rock roughness on tidal stream power extraction
}

\author{
by
}

\author{
Nicolas Guillou and Jérôme Thiébot
}

Full citation of this article is :

Guillou N., Thiébot J. (2016). The impact of seabed rock roughness on tidal stream power extraction. Energy, vol. 112, pp. 762-773, doi :

10.1016/j.energy.2016.06.053

Please note that this is an author-produced PDF of the draft of the manuscript submitted to Energy. The definitive publisher-authenticated version is available on the publisher Web site. 


\title{
The impact of seabed rock roughness on tidal stream power extraction.
}

\author{
Nicolas Guillou ${ }^{\mathrm{a}, *}$, Jérôme Thiébot ${ }^{\mathrm{b}}$ \\ ${ }^{a}$ Laboratoire de Génie Côtier et Environnement (LGCE), Cerema/DTecEMF/DS, 155 rue Pierre \\ Bouguer Technopôle Brest-Iroise - BP 5 - 29280 Plouzané, France \\ ${ }^{b}$ Normandie Univ., UNICAEN, LUSAC, EA4253, site universitaire de Cherbourg, rue Louis Aragon, \\ BP 78, F-50130 Cherbourg-Octeville, France
}

\begin{abstract}
Numerical assessments of environmental disturbances induced by a tidal farm project rely usually on local modifications of the friction coefficient over the area covered by a proposed array. Nevertheless, no study has investigated the sensitivity of predictions to surrounding seabed friction. The present investigation focuses on impacts of roughness parameterisation of rock outcrops, a typical seabed of tidal stream sites. A high-resolution depth-averaged circulation model is implemented in the Fromveur Strait off western Brittany, a region with strong potential for array development, integrating the heterogeneity of sediment bottom types. Rock roughness strongly influences initial predictions of tidal current and kinetic energy in the Strait with variations of available power up to $30 \%$. Tidal energy extraction induces noticeable reductions of tidal currents and bottom shear stresses up to $15 \mathrm{~km}$ from the array considered till surrounding sandbanks. Rock roughness impacts farm-induced modifications of tidal currents, bottom shear stresses and stream powers till north-eastern and southward edges of the Strait with major absolute differences identified in its central part. Surrounding sandbanks are finally suggested to variations of shear stresses from 9 to $17 \%$ over the Bank of the Four with possible implications on local sediment deposition.
\end{abstract}

Keywords: marine renewable energy, TELEMAC 2D, western Brittany, Sea of Iroise, Fromveur Strait, unstructured grid

\section{Introduction}

The exploitation of tidal stream power is currently considered as a promising solution for rising the proportion of marine renewable energy to the worldwide energy production $[1,2]$. Major well-known advantages are the highly predictable and regular characteristics of the resource, the substantial degree of modularity in extracting the energy [3], the high load fluid factor and the reduced visual impact of tidal stream devices in comparison with

\footnotetext{
*Corresponding author

Email addresses: nicolas.guillou@cerema.fr (Nicolas Guillou), jerome.thiebot@unicaen.fr (Jérôme Thiébot)

Preprint submitted to Energy 
wind or waves systems. Tidal kinetic power has thus attracted significant interest from leading developers of tidal energy converters (TEC) with numerous full-scale devices tested in the real environment [4]. Considering the increasing technical development of devices, the question of the hydro-environmental impact of tidal stream farms is of major interest to guarantee successful deployment in the marine environment. Indeed, besides a local modification of available power distribution, potential far-field effects are expected with modifications of hydrodynamics components and associated transport of particles at several kilometres from the proposed array $[5,6,7]$.

As observations in the real environment with tidal stream farms are not available today, investigations of far-field impacts rely nowadays on regional numerical modelling. Hydrodynamic effects of tidal stream devices, which generally take the form of horizontal axis turbines [8], are most of the time approached with an equivalent drag force term redistributing the sum of turbines' thrust and structural drag forces over the area covered by a proposed array $[9,10,11]$. Whereas uncertainties exist about parameterisations of drag coefficients, upstream velocities $[12,13]$ or wake-wake interactions within the array [14], these formulations provide a global assessment of tidal stream power extraction particularly suited for the early stages of a tidal farm project while restricting the computational costs of simulations. Numerical sensitivity studies to the array-drag coefficient have thus helped potential developers to optimize projects of stream farms in terms of size, thrust and structural drag coefficients and number of turbines [7, 15, 16].

Nevertheless, in spite of local sensitivity studies to array-drag coefficients, no additional investigation has been devoted to the influence of surrounding seabed friction on TEC-induced modifications. Indeed, numerical sensitivity studies have primarily focused on the regional influence of bottom friction on tides exhibiting, in continental shelf environments, its effects on currents amplitude and asymmetry, and transport of particles $[17,18,19]$. These aspects have however been set aside in numerical assessments of available tidal stream power and TEC effects assuming uniform bottom friction coefficients, based (1) on Manning-Strickler [7, 10] or Chezy [20] formulations in depth-averaged models or (2) on uniform quadratic friction law in three-dimensional approaches [21, 22, 23]. Further investigations about the influence of bottom friction, integrating the spatial heterogeneity of sediment bottom types, are thus necessary as (1) induced modifications of tidal stream array depend on initial estimates of current fields and (2) more significant effects are expected on predicted energy outputs and sediment transport rates which vary with a power of tidal current amplitude.

The present study investigates the numerical sensitivity of tidal stream power extraction to the parameterisation of bottom roughness. Bottom friction depends however on different settings and forcings including bed-sediment composition and morphology of the sea bottom [24], and influence of hydrodynamic processes such as interactions of wave and current bottom boundary layers [25]. Taking into account the difficulty to separate each contribution, the influence of time-variable bottom roughness is disregarded here focusing on effects of intrinsic seabed properties. The attention is devoted to sensitivity of numerical predictions to roughness parameter of rock outcrops, a typical seabed of tidal stream sites whose roughness is characterised by a relative uncertainty in relation to the shape of seabed features [24]. This sensitivity study will furthermore give further insights about the calibration of seabed roughness in numerical assessments of TEC effects at the early stages of a farm project.

After a description of the study site (Section 2.1), the emphasis is put on the theoret- 
ical formulation and implementation of hydrodynamic model (Section 2.2). Predictions are first assessed against available in-situ observations of current amplitude and direction (Section 3.1) exhibiting the local numerical sensitivity to roughness parameterisation of rock outcrops (Section 3.2). Synoptic effects on tidal current amplitude and associated kinetic energy are then evaluated in spring tidal conditions. Modifications induced by the presence of a tidal stream farm are finally investigated focusing on key parameters of maximum currents amplitude and available stream power $10 \mathrm{~m}$ above the seabed (the assumed technology hub height for the region considered), and bottom shear stress (Sections 3.3 and 3.4).

\section{Materials and methods}

\subsection{Study region}

The site of application is the Fromveur Strait, off western Brittany, separating the isle of Ushant from a group of islets and rock belonging to the Molène archipelago (Fig. 1). With annual peak velocities exceeding $4 \mathrm{~m} \mathrm{~s}^{-1}$ [26] and mean water depths of $50 \mathrm{~m}$, this location is one of the largest tidal stream resource along the coasts of France. A restricted area of interest of $4 \mathrm{~km}^{2}$ has thus been identified by the French government for the development of tidal farm projects. The exploitation of tidal kinetic energy from this site is a promising alternative for restricting current energy consumption of the isles of Ushant and Molène, currently based on expensive and polluting fuel power station. In this perspective, a horizontal axis turbine known as Sabella D10 is currently tested in the Fromveur Strait by the French company Sabella SAS and connected to the electricity grid of the isle of Ushant. This turbine with rated power output of $0.5 \mathrm{MW}$ for a tidal current velocity of $3 \mathrm{~m} \mathrm{~s}^{-1}$ is a first step toward the implementation of a tidal stream farm in the Strait.

Tide propagates from the Gulf of Biscay in the South towards the English Channel in the North travelling around western Brittany thus generating clockwise rotating currents in the area of interest. The Strait is furthermore characterised by a strong asymmetry of tidal currents with a north-eastern flood-dominated sector and a southward ebb dominated region [27]. This asymmetry, likely associated with the funnel shape configuration of the Strait, decreases toward the centre of the area where the tidal flow is balanced with equivalent magnitudes of flood and ebb components. The seabed presents finally a highly heterogeneous spatial distribution of bottom-sediment grain sizes characterised by a succession of gravel deposits and localised sand supplies [28] (Fig. 2). Rocky substrates cover the major part of shallow water areas surrounding islands and islets of the Ushant-Molène archipelago spreading over nearly all the north-eastern part of the Fromveur Strait. Surrounding seabeds in deep waters are dominated by gravel deposits with localised sand supplies over the sand banks of Ushant (point \#1, Fig. 1) and the Four (point \#2, Fig. 1) [29].

\subsection{Numerical model}

Simulations are performed with the bi-dimensional horizontal (2DH) model TELEMAC 2D (version $6 \mathrm{p} 3$ ) of the finite-element modelling system TELEMAC [31]. The major advantage of this simulation tool in comparison with other shallow-water models is the 


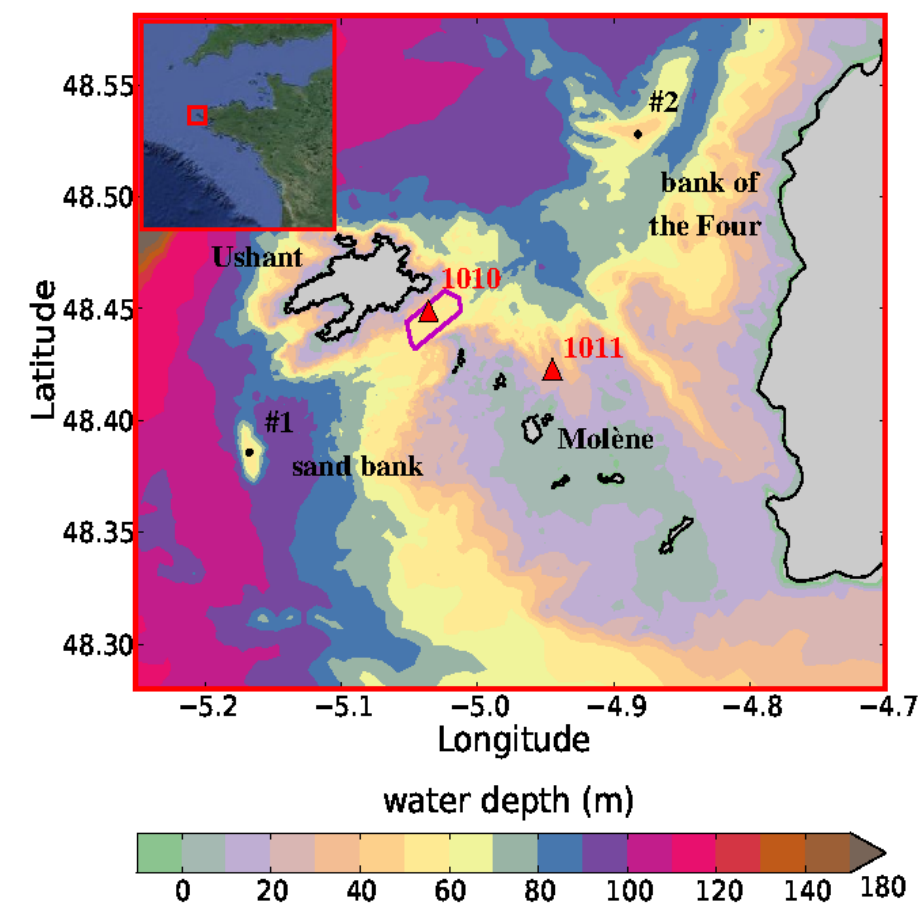

Figure 1: Bathymetry of Ushant-Molène archipelago with locations of available current meters $(\boldsymbol{\Delta})$. The magenta line in the Fromveur Strait delimits the region of interest for implementation of tidal stream devices. Water depth is relative to mean sea level.

use of an unstructured mesh particularly suited, in the present investigation, (1) to capture the complex coastline geometry of the isles and islets of Ushant-Molène archipelago and (2) to reach a refined spatial resolution over the tidal stream site while sparing prohibitive computational costs with a reduced number of grid nodes. TELEMAC 2D solves the shallow water Barré de Saint-Venant equations of continuity (Eq. 1) and momentum (Eq. 2), derived from the three-dimensional Navier-Stokes equations by averaging over the water column. The derivation of depth-averaged shallow-water equations rely on major assumptions of hydrostatic pressure, negligible vertical velocity and impermeability of the surface and the bottom. These equations take the following mathematical expressions :

$$
\begin{gathered}
\frac{\partial h}{\partial t}+\vec{u} \cdot \vec{\nabla}(h)+h \nabla \cdot \vec{u}=0 \\
\frac{\partial u_{i}}{\partial t}+\vec{u} . \vec{\nabla} u_{i}=-g \frac{\partial z_{s}}{\partial x_{i}}+\frac{1}{h} \nabla \cdot\left(h \nu_{t} \vec{\nabla} u_{i}\right)+S_{i}
\end{gathered}
$$

where $i=(x, y)$ with $x$ and $y$ the geographical coordinates, $t$ denotes time, $h$ is the total water depth, $g$ is the gravity acceleration, $\vec{u}=\left(u_{x}, u_{y}\right)$ is the depth-averaged velocity, $z_{s}$ is the water elevation and $\nu_{t}$ is the horizontal momentum diffusion coefficient computed 


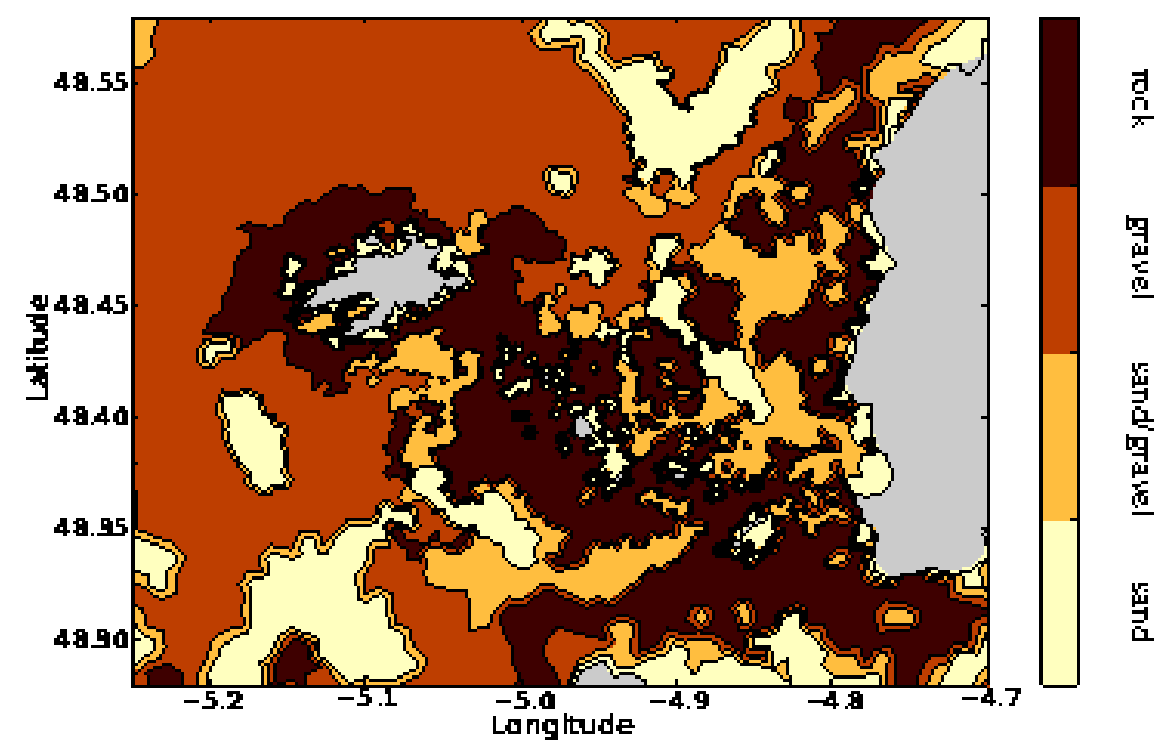

Figure 2: Sediment bottom types in and around the Fromveur Strait (adapted from Hamdi et al. [30]).

with a depth-averaged $k-\varepsilon$ model. $S_{i}$ accounts for sinks in the momentum equations related to (1) bottom friction $S_{b f}$ and (2) forces induced by TEC $S_{t e c}: \vec{S}_{i}=\vec{S}_{b f, i}+\vec{S}_{t e c, i}$. The default version of TELEMAC $2 \mathrm{D}$ has been modified to integrate these two sink terms. Associated computation methods retained here are briefly detailed hereafter.

Resulting from the average of Navier-Stokes equations along the water column, bottomfriction sink term is computed with the bottom shear stress $\tau_{b}$ as $S_{b f, i}=-\tau_{b, i} /(\rho h \cos (\alpha))$ where $\rho$ is the water density taken equal to $1025 \mathrm{~kg} \mathrm{~m}^{-3}$ and $\cos (\alpha)$ is the cosine reciprocal of the steepest slope at one point [31]. Assuming a logarithmic vertical velocity profile based on the law of the wall [32], the bottom shear stress is approached with a quadratic friction law: $\vec{\tau}_{b}=\rho C_{b}|u| \vec{u}$ where $C_{b}$ is the bottom drag coefficient. Its mathematical expression is given by

$$
C_{b}=\frac{\kappa^{2}}{\ln ^{2}\left[h /\left(e z_{0}\right)\right]}
$$

where $\kappa=0.4$ is the von Karman constant and $z_{0}$ is the roughness parameter defined as the height above the bed at which the fluid velocity is zero. As exhibited by Soulsby [32], coarse sand and gravels are characterised by hydrodynamically rough turbulent regimes in the marine environment. Considering the spatial distribution of sediment bottom types in the area of interest (Fig. 2), this assumption is retained here. The roughness parameter can thus be formulated in terms of the physical roughness of the bed neglecting influences of water viscosity and current speed [24]. The formulation of $C_{b}$ (Eq. 3) associates thus seabed friction with values of $z_{0}$ for different sediment bottom types.

Following most common numerical approaches [7, 9, 10, 21, 33, 34], tidal farm effects are included, at the scale of the tidal stream array, as an additional bed friction sink 
terms $S_{t e c}$ in the momentum equations: $S_{t e c, i}=-\tau_{\text {tec }} /(\rho h|u|) u_{i}$ where $\tau_{\text {tec }}$ is the stress term exerted by the turbine array on the flow. Its mathematical expression is obtained by averaging the total drag from turbines over the area covered by the proposed array $A_{e}: \tau_{t e c}=n F / A_{e}$ where $n$ is the total number of devices and $F$ is the individual total drag force from a single turbine. The individual drag is computed with the formulation proposed by Plew and Stevens [16] which includes the thrust and the structural drag of the device as

$$
\vec{F}=\frac{1}{2} \rho\left(C_{t} A+C_{d} A_{s}\right)|u| \vec{u}
$$

where $A$ is the area swept by blades, $A_{s}$ is the projected area of structural components in the vertical plane normal to the flow, and $C_{t}$ and $C_{d}$ are the thrust and structural drag coefficients, respectively. The thrust is considered over a cut-in speed $u_{c}$ from which the turbine is in function. Assuming that the energy lost to turbulence is constant relative to the power produced, the thrust coefficient is considered constant equal to $C_{t 0}$ between $u_{c}$ and the design speed $u_{d}$ at which device reaches its maximum power output $P_{\max }$. For higher velocities, $C_{t}$ decreases to limit power output and to protect the device generator. The thrust coefficient is thus parameterised as

$$
\begin{cases}C_{t}=0 & \text { for } \quad u<u_{c} \\ C_{t}=C_{t 0} & \text { for } \quad u_{c} \leq u \leq u_{d} \\ C_{t}=\frac{C_{t 0}}{C_{p 0}} \frac{2 P_{\max }}{\rho A u^{3}} & \text { for } \quad u>u_{d}\end{cases}
$$

where $C_{p 0}$ is the power coefficient. Devices' parameterisations are taken from Plew and Stevens [16]. The blade diameter is taken equal to $18.6 \mathrm{~m}$ corresponding to a total swept area $A \simeq 272 \mathrm{~m}^{2}$. The area of structural components is assumed to be $10 \%$ of the turbine swept area $\left(A_{s}=0.1 A\right)$ while a high value of the drag coefficient $C_{d}=0.9$ is adopted to integrate effects of surface fouling. Devices are in function for flow speed over $u_{c}=1 \mathrm{~m} \mathrm{~s}^{-1}$. The constant value of the thrust coefficient is finally taken equal to $C_{t 0}=0.8$. The design speed and maximum power output have however been reviewed to be consistent with surrounding hydrodynamic conditions and planned stream devices in the Fromveur Strait: $P_{\max }=1 \mathrm{MW}$ and $u_{d}=2.8 \mathrm{~m} \mathrm{~s}^{-1}$ corresponding to a power coefficient $C_{p 0}=0.31$.

\subsection{Setup}

TELEMAC 2D is set up on an unstructured computational grid covering the western extend of Brittany, and comprising 19068 nodes and 37019 triangular finite elements with a size ranging from $10 \mathrm{~km}$ at offshore boundaries to less than $50 \mathrm{~m}$ in the Fromveur Strait (Fig. 3). The geographical limits of the domain are similar to the grid used by Guillou and Chapalain $[35,36]$. The bathymetry includes different databases among which are (1) the regional database of Loubrieu [37] with a spatial resolution of $1 \mathrm{~km}$ and (2) the highresolution coverage of the Ushant-Molène archipelago established during the Litto3D project [38]. From the offshore extent of the isle of Ushant to the eastern boundary, sediment bottom types are determined on the basis of the map established by Hamdi et al. [30] (Ifremer, "Agence des Aires Marines Protégées"). If a computational grid node is located inside a patch identified in this sedimentological cartography, the corresponding nature of the seabed is assigned to this node. The associated roughness parameter is then prescribed according to observations of $z_{0}$ for different bottom types compiled by Soulsby 


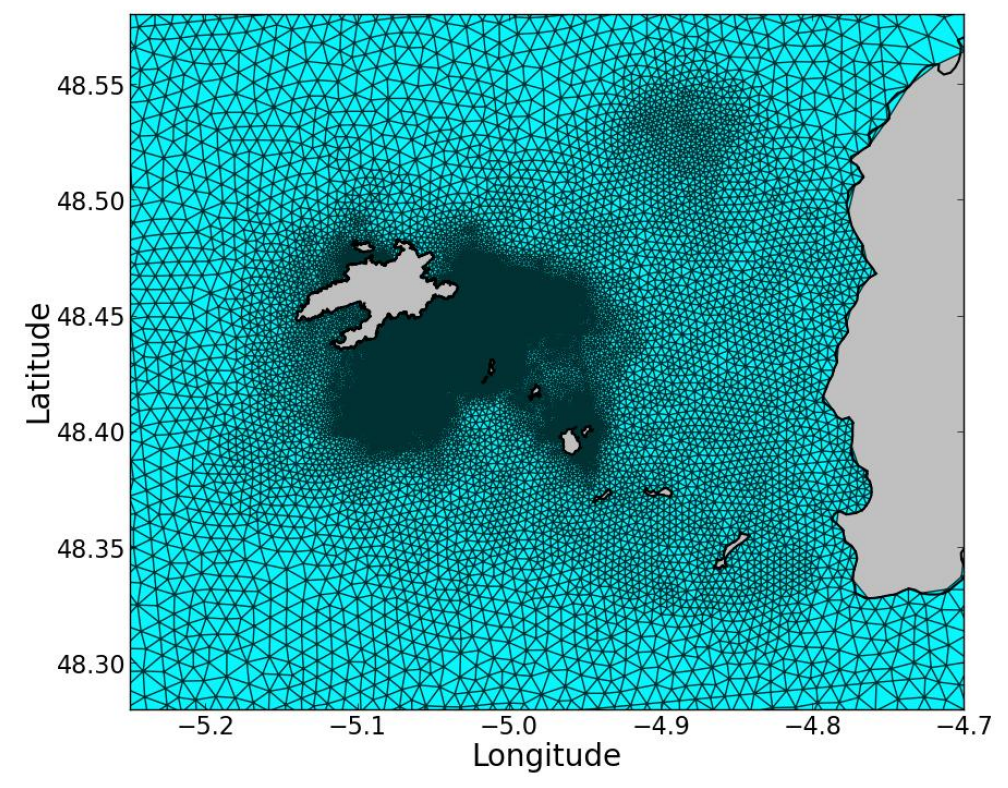

Figure 3: Detailed view of the unstructured computational grid in and around the Fromveur Strait.

[24]. The sensitivity of numerical predictions is evaluated with seven values of $z_{0}$ in areas of rock outcrops: $3.5,5.0,10.0,15.0,20.0,30.0$ and $50.0 \mathrm{~mm}$. Following parameterisations retained in regional tidal model covering the western extend of Brittany [19, 39, 40], the bottom roughness parameter is set to an uniform value of $z_{0}=3.5 \mathrm{~mm}$ offshore where the nature of the seabed can not be identified from the sedimentological cartography [30]. The model is implemented with a time step of $1 \mathrm{~s}$ neglecting influences of atmospheric pressure, wind velocity components and surface-gravity waves. Simulations are driven by 13 major harmonic tidal constituents $\left(\mathrm{K}_{1}, \mathrm{O}_{1}, \mathrm{P}_{1}, \mathrm{Q}_{1}, \mathrm{M}_{2}, \mathrm{~S}_{2}, \mathrm{~N}_{2}, \mathrm{~K}_{2}, \mathrm{M}_{4}, \mathrm{MS}_{4}, \mathrm{MN}_{4}\right.$, $\mathrm{M}_{m}, \mathrm{M}_{f}$ ) of the TPXO7.2 database covering the area of interest with a spatial resolution of $0.25^{\circ}$ [41]. Prescribed sea level variations and free normal velocities are considered at the open boundaries. When considered, tidal stream devices are placed in the restricted area of interest identified in the Fromveur Strait (Fig. 1). According to Thiébot et al. [10], a density of 50 machines per $\mathrm{km}^{2}$ is retained here which corresponds to a total of 207 turbines placed in the tidal farm. Numerical results are evaluated with a series of statistical parameters including the standard deviation $\mathrm{STD}=\sqrt{\frac{1}{N} \sum_{i=1}^{i=N}\left|y_{i}-\bar{y}\right|^{2}}$, the mean relative error $\mathrm{MRE}_{\mathrm{rel}}=\mathrm{MRE} / \bar{x} \times 100$ with $\mathrm{MRE}=\frac{1}{N} \sum_{i=1}^{i=N}\left(y_{i}-x_{i}\right)$ and the index of agreement $\mathrm{RE} \mathrm{[42]} \mathrm{where} N$ is the number of data in the discretised series considered, $\left(x_{i}\right)$ and $\left(y_{i}\right)$ represent the two sets of measured and simulated values, and $\bar{x}$ and $\bar{y}$ are the mean values of observed and simulated data, respectively. Positive values of MRE and $\mathrm{MRE}_{\text {rel }}$ indicate thus a mean overestimation of observations whereas negatives values account of a mean underestimation. $\mathrm{RE}$ varies between 0 and 1 . Its equals to unity for perfect agreement. 


\section{Results and discussion}

\subsection{Evaluation of model predictions}

The evaluation of model predictions is performed against available in-situ observations of current amplitude and direction at points 1010 and 1011 (Fig. 1 and Table 1). These observations have been acquired by a $600 \mathrm{kHz}$ RDI ADCP (Acoustic Doppler Current Profiler) deployed by the French Navy SHOM ("Service Hydrographique et Océanographique de la Marine"). Measurements period correspond to different neapspring tidal conditions: (1) from 19 March to 2 April 1993 at point 1010 and (2) from 14 May to 11 June 1993 at point 1011. Whereas ADCP data are available in $2 \mathrm{~m}$ bins distributed throughout the water column at both measurement points, comparisons between observations and predictions are performed $10 \mathrm{~m}$ above the bed as this corresponds to the operating height of planned horizontal axis turbines in the Strait. Values $10 \mathrm{~m}$ above the bed are computed from predicted depth-averaged velocities assuming a vertical logarithmic profile in the water column. Fig. 4 presents the comparison for predictions with a roughness parameter $z_{0}=20 \mathrm{~mm}$ over rock outcrops. An overall good agreement is obtained for the current amplitude at point 1010 with an index of agreement $\mathrm{RE}=0.98$. Predictions reproduce also the weak asymmetry of tidal current in the Strait characterised by slightly larger amplitudes of south-west directed components at point 1010 [27]. This asymmetry is however far more pronounced at point 1011 with (1) strong and short north-eastern components and (2) reduced long-lasted south-western velocities. In spite of higher differences than at point 1010 with an index $R E=0.78$, numerical results reproduce the observed asymmetry of current amplitude at point 1011, seemingly associated with the formation of a tidal recirculation in the north of the isle of Molène. Whereas slight deviations are identified in current directions, simulated values appear consistent with observations, reproducing at both measurement sites abrupt changes between south-west and north-east directed velocities. This local assessment of model's performances is supplemented by a regional comparison of predictions with numerical estimations provided by the SHOM at the scale of Ushant-Molène archipelago [43] (Fig. $5)$. This synoptic evaluation confirms the ability of the model to approach temporal and spatial variabilities of spring tidal currents in the area of interest.

Table 1: Description of current measurement campaigns.

\begin{tabular}{ccccc}
\hline Points & \multicolumn{2}{c}{ Coordinates } & Water depths & Periods \\
& Lon. & Lat & $(\mathrm{m})$ & of measurements \\
\hline 1010 & $5.036^{\circ} \mathrm{W}$ & $48.449^{\circ} \mathrm{N}$ & 53 & $19 / 03 / 1993 \rightarrow 02 / 04 / 1993$ \\
1011 & $4.945^{\circ} \mathrm{W}$ & $48.423^{\circ} \mathrm{N}$ & 29 & $14 / 05 / 1993 \rightarrow 11 / 06 / 1993$ \\
\hline
\end{tabular}

\subsection{Effects of seabed roughness without turbines}

Local predictions appear however sensitive to the value retained for the roughness parameter over rock outcrops (Fig. 6). Increasing $z_{0}$ results thus in a decrease of tidal current amplitude at both measurement points with associated mean relative errors $\mathrm{MRE}_{\mathrm{rel}}$ decreasing from 2.2 to $-2.8 \%$ at point 1010 , and from 24.0 to $11.3 \%$ at point 1011 . As predictions of current direction at point 1010 are barely sensitive to bottom roughness 

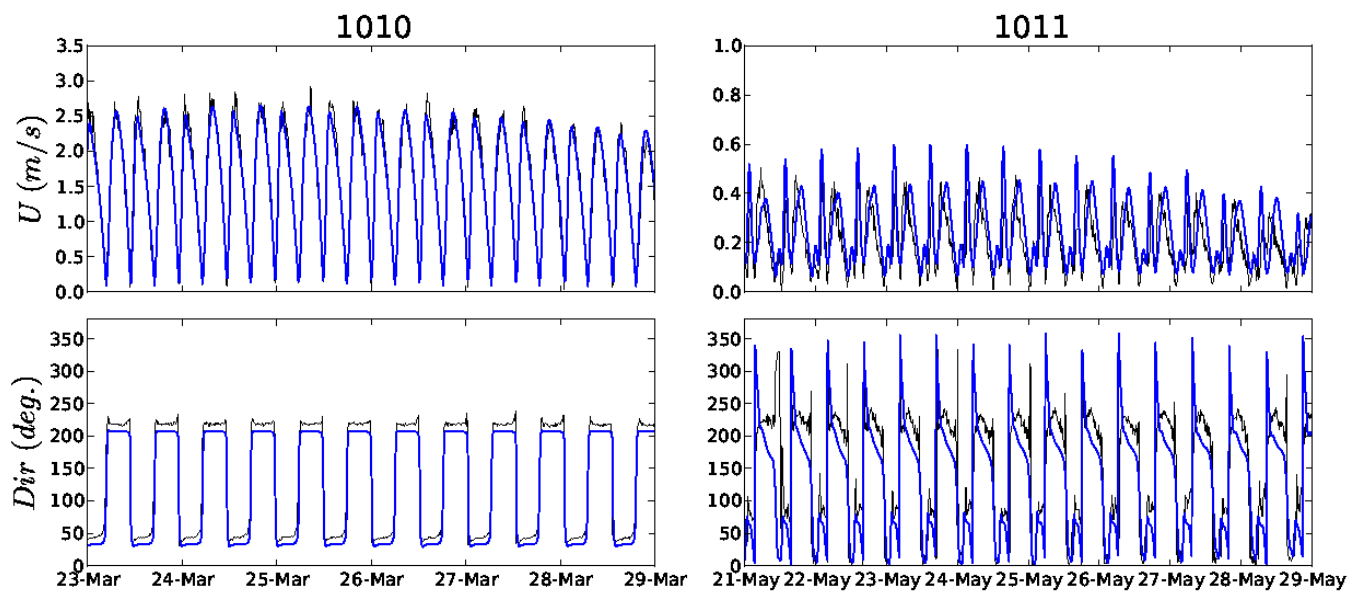

Figure 4: Measured (black line) and computed (for $z_{0}=20 \mathrm{~mm}$ over rock outcrops) (blue line) time series of the amplitude and direction (anticlockwise convention from the East) of the current $10 \mathrm{~m}$ above the bed at points 1010 and 1011.

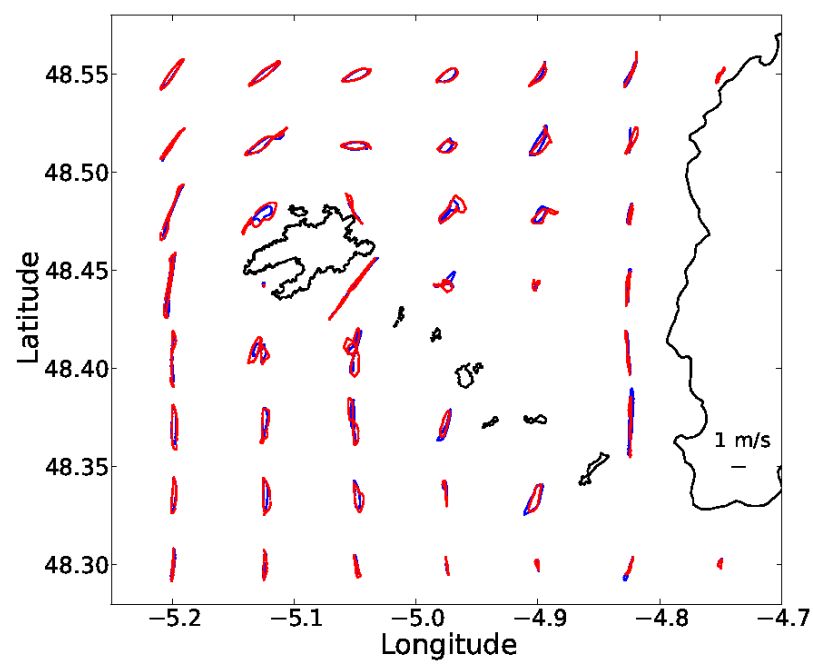

Figure 5: Current ellipses at $10 \mathrm{~m}$ above the bed for mean spring tidal conditions (blue) issued from the SHOM database [43] and (red) predicted in configuration with $z_{0}=20 \mathrm{~mm}$ over rock outcrops.

parameterisation, a foremost calibration of $z_{0}$ over rock outcrops is determined on the basis of predicted amplitudes at this measurement point. Best comparisons are obtained for roughness parameters between 15 and $20 \mathrm{~mm}$ with $\mathrm{MRE}_{\text {rel }}$ between -0.47 and $0.08 \%$. More significant sensitivity to roughness of rock outcrops is however obtained at point 1011. Whereas the mean relative error of $|U|$ is found to decrease by increasing the roughness parameter, best estimations of current direction are obtained for values of $z_{0}$ 
below $20 \mathrm{~mm}$. As the index of agreement RE of predicted current directions at point 1011 reaches a maximum value for $z_{0}=30 \mathrm{~mm}$, a bottom roughness parameter of $20 \mathrm{~mm}$ is considered as the best compromise to provide optimal predictions of tidal currents at both measurement points.

Nevertheless, whereas this analysis confirms the evaluation of model predictions established in Fig. 4, a relative uncertainty still remains about the choice of the roughness parameter. In the present investigation, the two measurement points have helped to refine the calibration of $z_{0}$ over rock outcrops. But comparisons have also exhibited different sensitivity degrees of numerical results to bottom roughness parameterisation with possible implications on the calibration of $z_{0}$ over rock outcrops. Relying only on measurements at point 1010, satisfactory predictions can thus be established for $z_{0}$ values of 3.5 and $50 \mathrm{~mm}$ (Fig. 7-a) while more significant differences appear at point 1011 (Fig. 7b). Additional measurements are thus required to confirm the calibration of $z_{0}=20 \mathrm{~mm}$ over rock outcrops integrating, in particular, the local sensitivity of measurement points to bottom roughness. These observations should preferentially be conducted in tidal dominated conditions as a first step towards the investigation of complementary effects of wind and waves.

In this perspective, the sensitivity of model predictions to $z_{0}$ over rock outcrops is analysed during mean spring tidal conditions. Such analysis identifies, in particular, synoptic effects associated with bottom roughness of rock outcrops of noticeable interest for numerical assessment of tidal currents and stream powers at the early stages of a farm
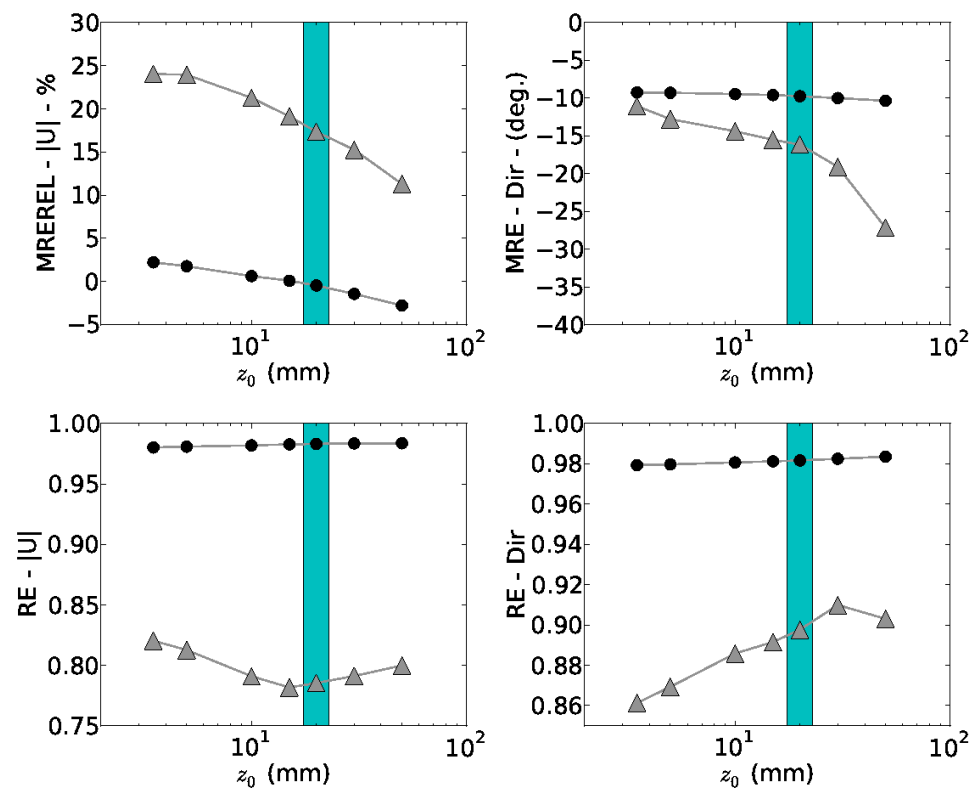

Figure 6: Statistical parameters associated with predictions of amplitude and direction of currents $10 \mathrm{~m}$ above the bed at points $1010(\mathbf{O})$ and 1011 ( $\mathbf{\Delta})$ for different values of the bottom roughness parameter $z_{0}$ over rock outcrops. The vertical light blue bar shows the configuration with $z_{0}=20 \mathrm{~mm}$ over rock outcrops. 

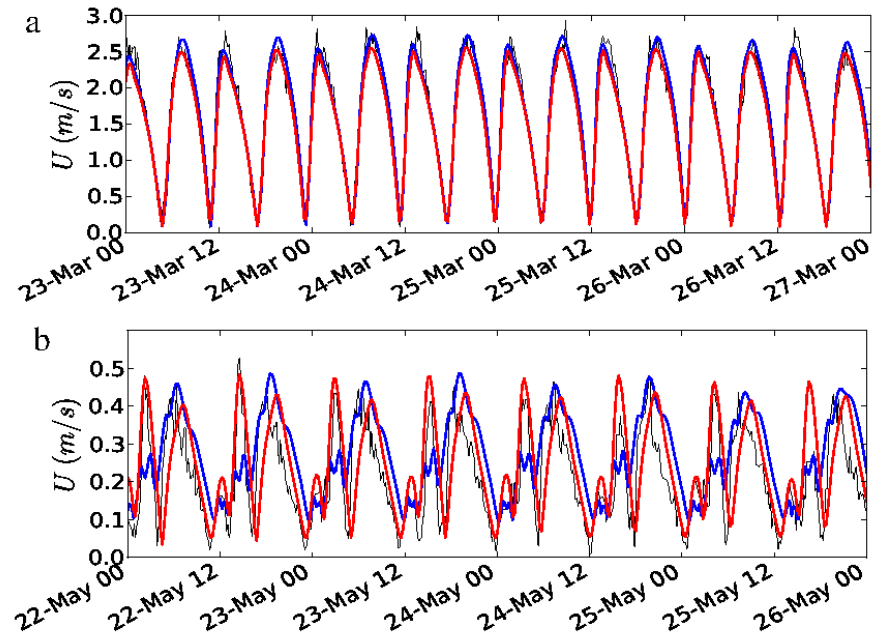

Figure 7: Measured (black line) and computed (with $z_{0}=3.5 \mathrm{~mm}$, blue line, and $z_{0}=50 \mathrm{~mm}$, red line, over rocks outcrops) time series of current amplitude $10 \mathrm{~m}$ above the bed at points (a) 1010 and (b) 1011 during spring conditions of March and May 1993.

project (Figs. 8 and 9). Significant differences are obtained at the scale of Ushant-Molène archipelago with an overall reduction of maximum tidal current amplitude by increasing $z_{0}$ values over rock outcrops (Fig. 8). In narrow straits between islets and isles of Molène archipelago, depth-averaged currents experience thus a reduction of maximum velocities over $30 \%$ by rising $z_{0}$ from 3.5 to $20 \mathrm{~mm}$. Strong differences are also identified in the north-eastern and southward edges of the Fromveur Strait with a reduction of maximum currents amplitudes up to $0.6 \mathrm{~m} \mathrm{~s}^{-1}$. Nevertheless, the central area of the Strait presents modifications restricted below $6 \%$ (less than $0.2 \mathrm{~m} \mathrm{~s}^{-1}$ ) as exhibited with the local sensitivity study at point 1010 (Fig. 6). This spatial distribution may be associated with the asymmetry of tidal currents in the Strait [27] (Section 2.1). Roughness of rock outcrops in the central Strait impacts thus north-east directed current components in the northern part of the Strait while the reverse happens in the southward region. As tidal flow is balanced in the central Strait with equivalent magnitudes of flood and ebb components, only a reduced area of rock outcrops impacts currents over this area. The area with a reduced sensitivity corresponds thus to the region of rock outcrops identified in the central Strait (Fig. 2). Besides this remarkable evolution, predictions exhibit, in the north-eastern edge of the Strait, an adjacent area to the main flow where current amplitudes experience a reverse trend in comparison with the global evolution. Possible compensation effects of the flow passing the Strait may explain this spatial distribution. In spite of the restricted local sensitivity of tidal currents in the central Strait, significant differences are obtained for predictions of available tidal stream powers over the area identified for array implementation (Fig. 9). Over this area, mean and maximum tidal kinetic energies are thus reduced in the same proportion, by around $30 \%$, between configurations with $z_{0}=3.5$ and $50 \mathrm{~mm}$ over rock outcrops. This result exhibits the great sensitivity of numerical assessment of available stream power to bottom roughness 
of rock outcrops in the Fromveur Strait.

\subsection{Effects of tidal stream power extraction}

Prior to the investigation of rock roughness impacts on tidal stream power extraction, effects of the turbine array are analysed during mean spring tidal conditions, for the reference configuration with $z_{0}=20 \mathrm{~mm}$ over rock outcrops, focusing on modifications of current amplitude, bottom shear stress and available stream power. Tidal power extraction has a negligible influence on water level confirming previous numerical regional assessments of turbines effects [7, 10, 16, 44]. More significant differences are however obtained on current amplitude, particularly noticeable along the flow passing the Strait (Fig. 10). Predicted modifications are typical of differences induced on velocities with a turbine array $[7,45,46]$. Current amplitude is thus reduced inside the array, and both upstream and downstream the tidal farm while it is accelerated on the sides of the flow passing the farm location. The increase in current magnitude on both sides of the farm is attributed to the fact that flow not harnessed by the array is conveyed in a restricted area [44]. The perturbation magnitude reaches $0.7 \mathrm{~m} \mathrm{~s}^{-1}$ at ebb and flood peaks for the tidal array configuration retained here. Confirming regional numerical investigations performed by Ahmadian et al. [7] and Neill et al. [9], noticeable changes in velocity magnitudes, over $10 \%$ of mean depth-averaged currents during a spring tidal cycle (Figs. 11-a and b), occur furthermore at a distance of several kilometres from the array. These modifications, which correspond to a decrease by nearly $0.10 \mathrm{~m} \mathrm{~s}^{-1}$ of tidal current amplitude, appear at around $10 \mathrm{~km}$ from the tidal farm for north-east directed currents while it extends up to $15 \mathrm{~km}$ from the site of extraction for south-west directed velocities. Such asymmetry may be related to the spatial north-eastern and southward extents of maximum tidal current velocities in the Fromveur Strait as exhibited in Fig. 8.

Whereas further investigations may be conducted on associated sediment transport rates and local modifications of seabed morphology relying on transport models $[9,10]$, difficulties associated with the calibration of such simulation rise numerous uncertainties for the investigation of TEC effects. Instead, modification of maximum bottom shear stress $\tau_{b, \max }$ is provided as an indicator of changes induced in sediment transport, particularly relevant for estimating seabed sediments motion (Figs. 11-c and -d). Induced modifications of $\tau_{b, \max }$ are highly correlated with differences identified for tidal currents confirming predictions established by Thiébot et al. [10] in the Alderney Race (English Channel). In the present investigation, the extraction of tidal stream energy results thus in a reduction of maximum values of $\tau_{b}$ up to $30 \%$ in the Fromveur Strait (Fig. 11-d) corresponding to a decrease of bottom shear stress over $10 \mathrm{~N} \mathrm{~m}^{-2}$ in its central part. Weaker modifications appear however off the Strait (modification of $\tau_{b, \max }$ smaller than $4 \%$ over the bank of Ushant). Nevertheless, noticeable effects remain over the bank of the Four with a reduction of $\tau_{b, \max }$ up to $12 \%$. Such evolution of local bottom shear stress may be associated with increased deposition of sediments over this sand bank.

Available tidal stream power experiences finally a significant reduction in the Fromveur Strait by nearly $30 \%$ for $P_{\text {mean }}$ and $P_{\text {max }}$ during a mean spring tidal cycle (Fig. 12). This reduction exceeds the theoretical power output of the tidal stream array. This is partly explained by the effects of thrust and structural drag forces on the flow. Firstly, as exhibited by the ratio between the thrust and power coefficients $\left(C_{t 0} / C_{p 0} \simeq 2.6\right)$ (Eq. $5)$, more power is extracted from the available resource than outputted by the device at 

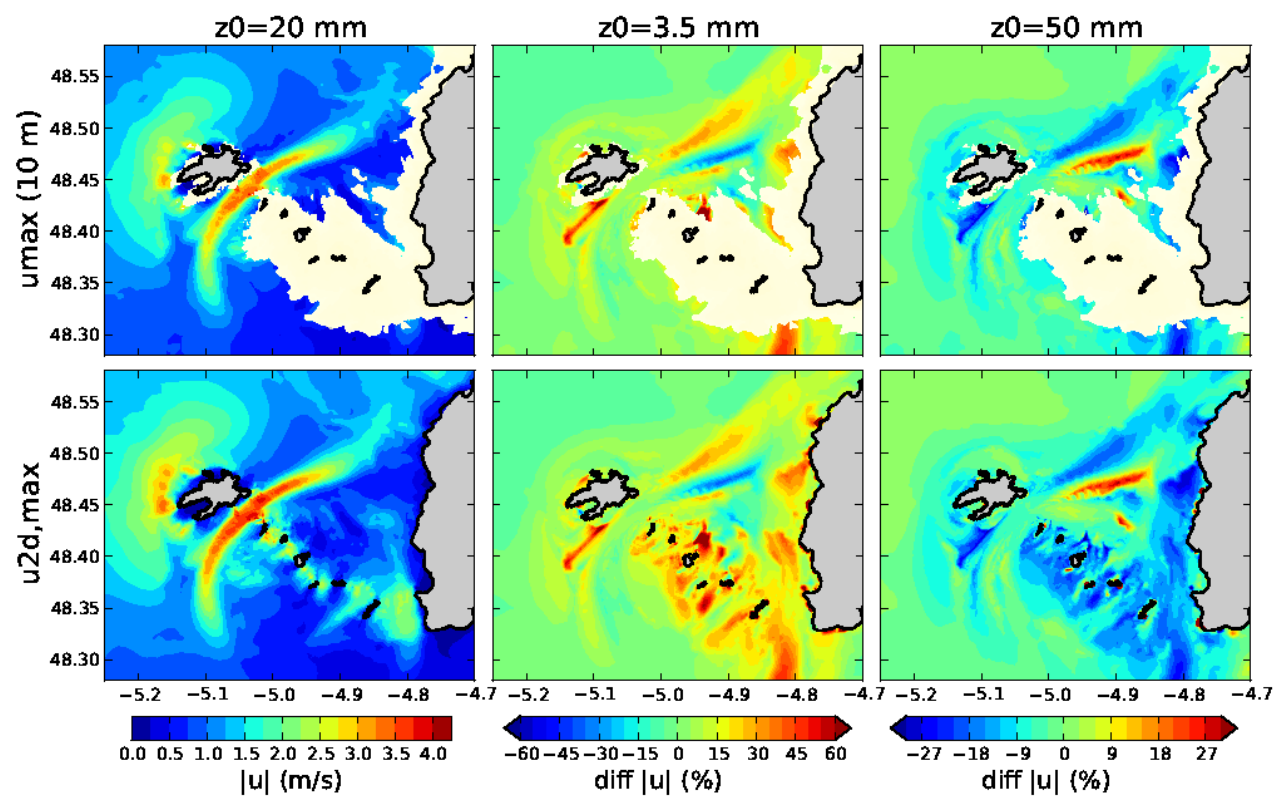

Figure 8: (left) Maximum amplitudes of currents $10 \mathrm{~m}$ above the bed (umax $(10 \mathrm{~m})$ ) and of depthaveraged currents (u2d,max) during mean spring tidal conditions for simulation with $z_{0}=20 \mathrm{~mm}$ over rock outcrops. (middle and right) Relative differences with respect to this configuration for simulations with $z_{0}=3.5$ and $50 \mathrm{~mm}$ over rock outcrops. Predictions of currents $10 \mathrm{~m}$ above the bed are shown for mean water depths over $20 \mathrm{~m}$. 

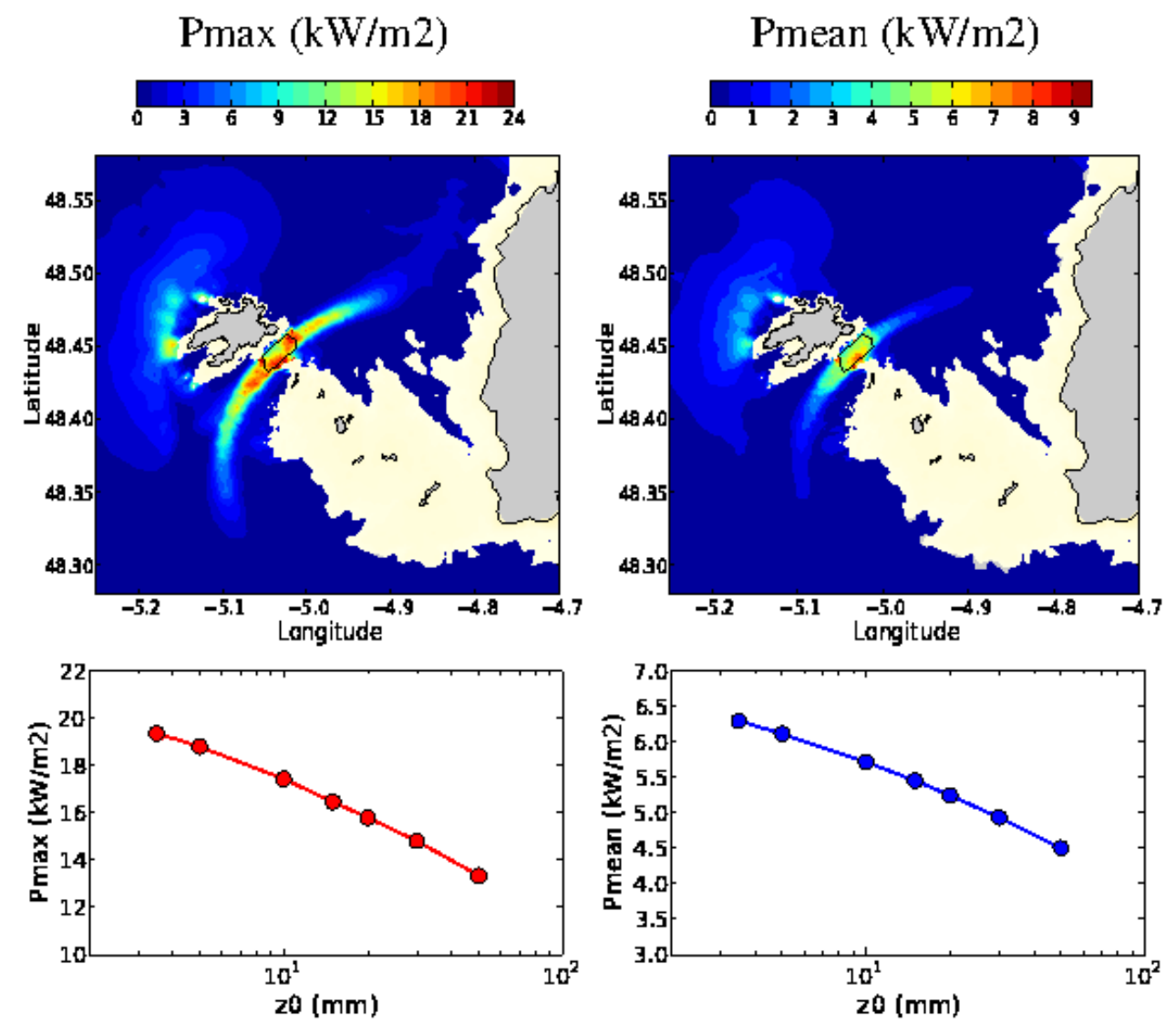

Figure 9: (top) Maximum and mean predicted tidal stream powers $10 \mathrm{~m}$ above the bed during mean spring conditions for the reference configuration $\left(z_{0}=20 \mathrm{~mm}\right.$ over rock outcrops). Predictions are shown for mean water depths over $20 \mathrm{~m}$. (bottom) Evolution of maximum and mean spring tidal stream powers averaged over the area identified for array implementation for different values of $z_{0}$ over rock outcrops. 


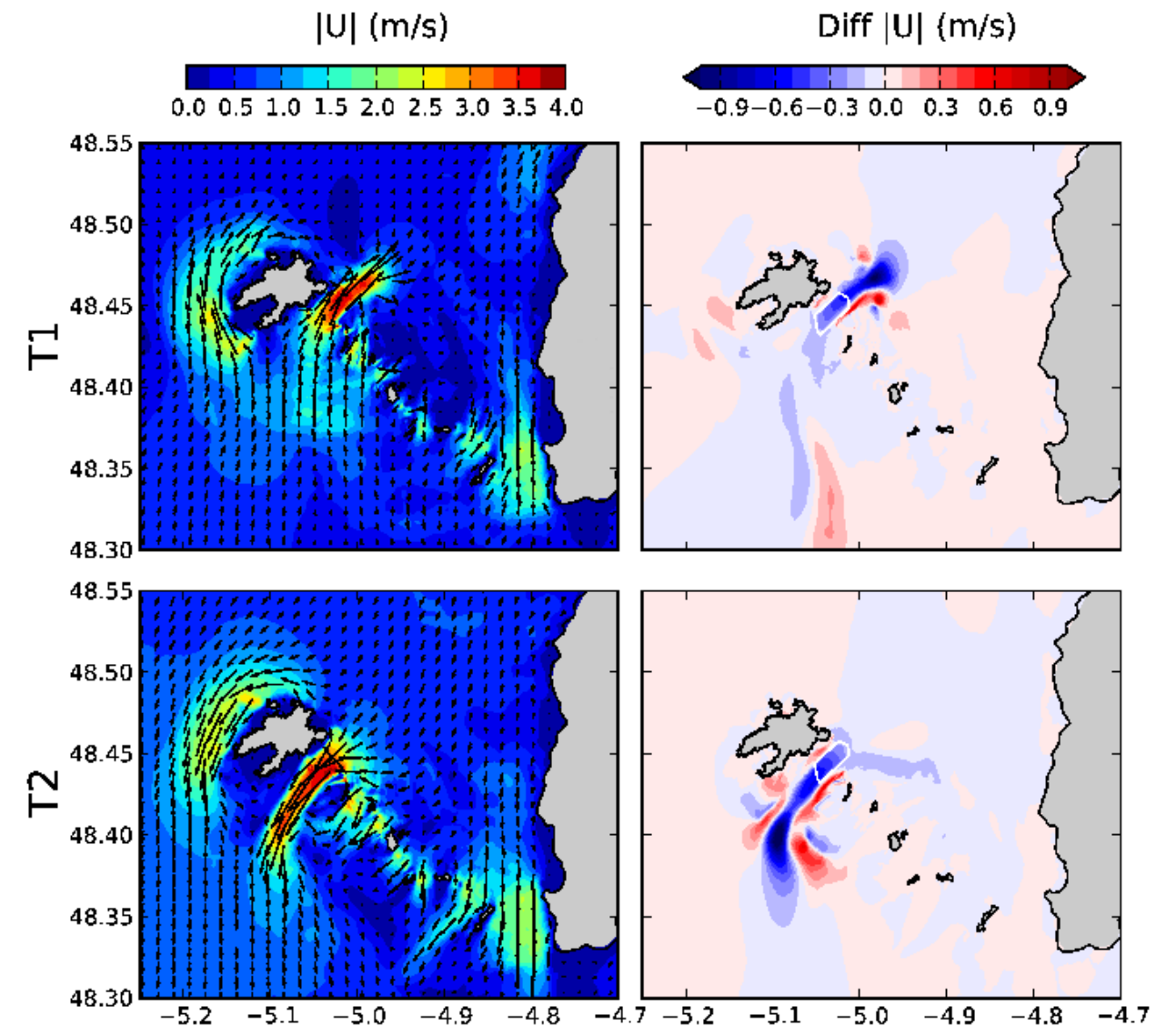

Figure 10: (left) Depth-averaged currents for the reference configuration $\left(z_{0}=20 \mathrm{~mm}\right.$ over rock outcrops) without tidal stream array and (right) differences in amplitude of depth-averaged currents by integrating effects of tidal stream array at times of flood (T1) and ebb (T2) peaks in the Fromveur Strait. Positive and negative values account for increase and reduction of currents with TEC, respectively. 

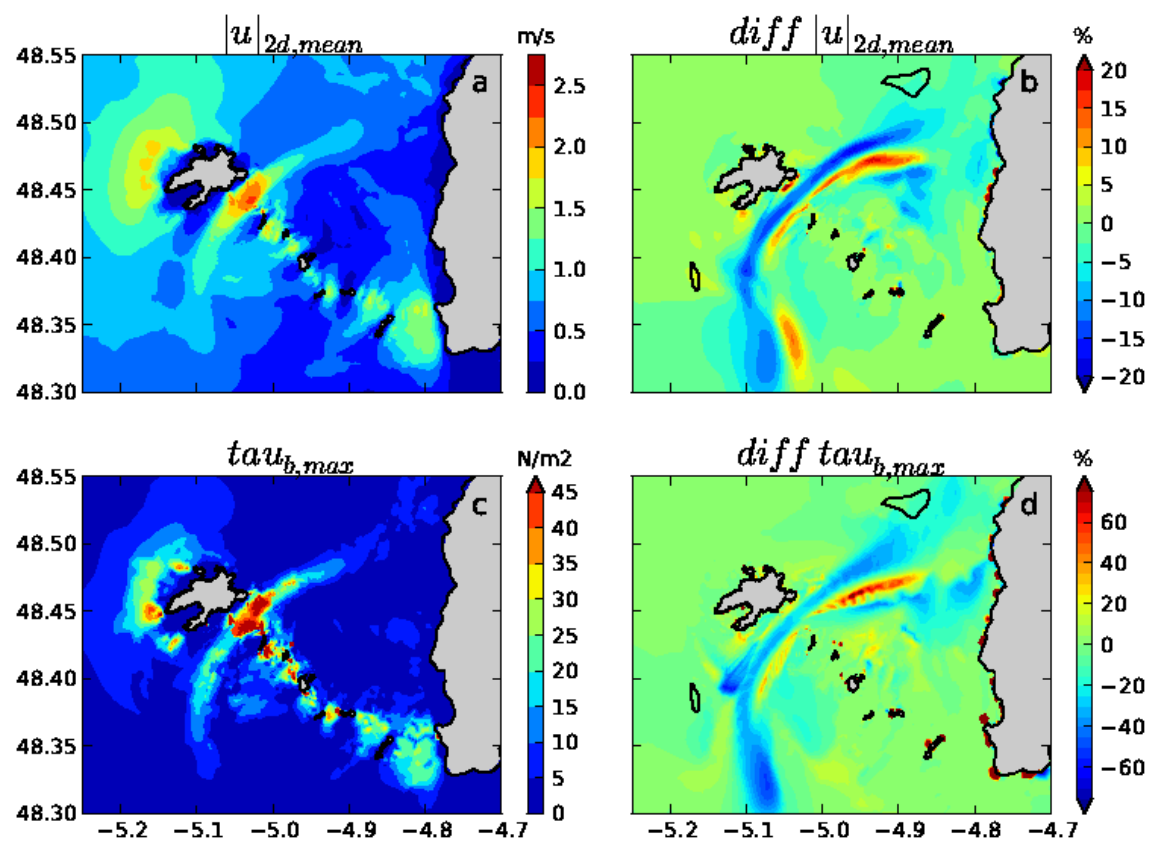

Figure 11: (a) Mean depth-averaged currents and (c) maximum bottom shear stresses during a spring tidal cycle for the reference configuration $\left(z_{0}=20 \mathrm{~mm}\right.$ over rock outcrops) without tidal stream array. Relative differences, expressed in percentages of values without TEC, in predictions of (b) mean depth-averaged currents and (d) maximum bottom shear stresses between configurations integrating and neglecting tidal stream array. The black lines in Figs. b and d show the positions of sand banks identified in Fig. 1. 
high velocities exceeding the design speed $u_{d}$. As the Fromveur Strait is characterised by strong velocities exceeding $u_{d}$ over a large part of the tidal stream array at flood and ebb peaks, the ratio $C_{t 0} / C_{p 0}$ results in a significant reduction of available tidal stream power at the scale of the farm. Secondly, the contribution of structural drag forces acts also on the reduction of available power. According to Plew and Stevens [16], this effect may be significant resulting in overestimation of peak and average power productions during spring tides when neglected.
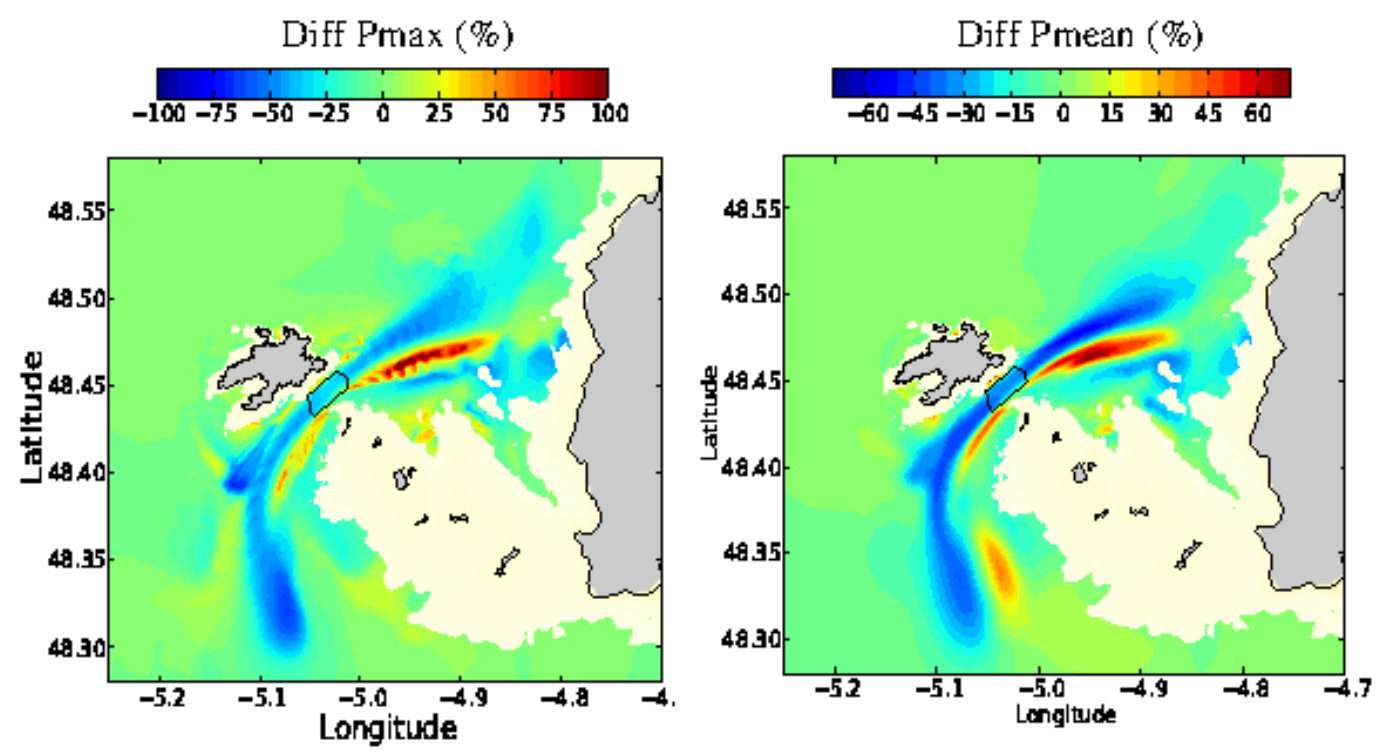

Figure 12: Relative differences, expressed in percentages of values without TEC, in predictions of maximum and mean tidal stream powers $10 \mathrm{~m}$ above the bed during a spring tidal cycle for the reference configuration ( $z_{0}=20 \mathrm{~mm}$ over rock outcrops) between simulations integrating and neglecting tidal stream array. Predictions are shown for mean water depths over $20 \mathrm{~m}$.

\subsection{Sensitivity of tidal stream energy extraction to rock bottom roughness}

The impact of rock bottom roughness on tidal stream power extraction is investigated expressing induced modifications as ratios to the reference configurations without TEC. Fig. 13 shows relative differences induced by TEC in predictions of maximum current and stream power $10 \mathrm{~m}$ above the bed, and bottom shear stress during a mean spring tidal cycle for three values of $z_{0}$ over rock outcrops: $3.5,15$ and $50 \mathrm{~mm}$. Bottom roughness parameterisation has a reduced influence on the overall spatial distribution of TEC-induced differences for the three key indicators considered here. Indeed, major TEC-induced differences remain restricted along the extension of the Fromveur Strait as identified in section 3.3 (Figs. 11 and 12). Rock bottom roughness influences however relative differences in the north-eastern and southward edges of the Strait as exhibited by the standard deviation of theses quantities (Fig. 14). In the north-eastern part, major changes are obtained over the acceleration area appearing on the side of the flow passing the Strait which tends to deviate slightly towards the south and lessen by increasing 
roughness of rock outcrops. In the southward region, main modifications concern the deceleration area with noticeable effects appearing at the eastern side of the bank of Ushant.

Nevertheless, modifications appearing at the north-eastern and southward edges of the flow passing the Strait concern reduced magnitudes of current amplitude, bottom shear stress and stream power in comparison with values in the central part of the Strait (Figs. 8, 9 and 11-c). In this central area, rock roughness parameterisation has thus a strong influence on magnitudes of induced modifications as exhibited by the evolution of available tidal stream powers over the area identified for array implementation (Fig. 15). The central part of the Strait presents furthermore a pronounced sensitivity of shear stress predictions to bottom roughness values of rock outcrops. Whereas $\tau_{b}$ decreases by $9 \mathrm{~N} \mathrm{~m}^{-2}$ over this central area for $z_{0}=3.5 \mathrm{~mm}$ over rock outcrops, the reduction exceeds $14 \mathrm{~N} \mathrm{~m}^{-2}$ for $z_{0}=50 \mathrm{~mm}$. This result exhibits the noticeable sensitivity of bottom shear-stress predictions to bottom roughness in the central part of the Strait.

Predictions over the bank of the Four (point \#2) remain finally sensitive to bottom roughness parameterisation of rock outcrops. Over this area, the induced reductions of maximum currents amplitude $10 \mathrm{~m}$ above the bed vary thus in the range $4.6-8.8 \%$ depending on $z_{0}$ values retained over rock outcrops (Table 2). Differences are exacerbated in the range $9.0-16.9 \%$ for $\tau_{b}$ predictions which vary with the square of current amplitude. Over this area, the global tendency is a reduction of induced variations by increasing bottom roughness values. The magnitude of induced modifications of sediment transport rates and associated deposition over the bank of the Four will thus strongly depend on values retained for $z_{0}$ over rock outcrops. Variations obtained over the bank of Ushant (point \#1) are finally restricted below $2.0 \%$ for maximum current and $4.0 \%$ for maximum bottom shear stress exhibiting a reduced sensitivity to tidal energy extraction and bottom roughness parameterisation over rock outcrops (Table 3).

\section{Conclusions}

The depth-averaged tidal circulation model TELEMAC 2D has been implemented in a region off western Brittany, that has been identified with strong potential for tidal array development, in order to investigate and evaluate the impact of bottom roughness parameterisation of rock outcrops on effects of tidal kinetic energy extraction. Numerical predictions are assessed against available in-situ observations of tidal currents amplitude and direction at two locations in the Fromveur Strait and shallow waters off the isle of Molène. The main outcomes of the present study are as follow.

1. Significant differences are obtained for initial predictions of tidal currents and associated stream powers, during a mean spring tidal cycle, particularly noticeable in the north-eastern and southward edges of the Strait with a reduction of maximum depth-averaged velocities over $30 \%$ between configurations with $z_{0}=3.5$ and $20 \mathrm{~mm}$ over rock outcrops. Rock bottom roughness influences also the initial estimates of tidal kinetic energy in the area identified for stream-array implementation with a reduction of available power by $30 \%$ by rising $z_{0}$ from 3.5 to $50 \mathrm{~mm}$.

2. Tidal kinetic energy extraction results in significant reduction of tidal current amplitude, bottom shear stress and available stream power inside the array and both 


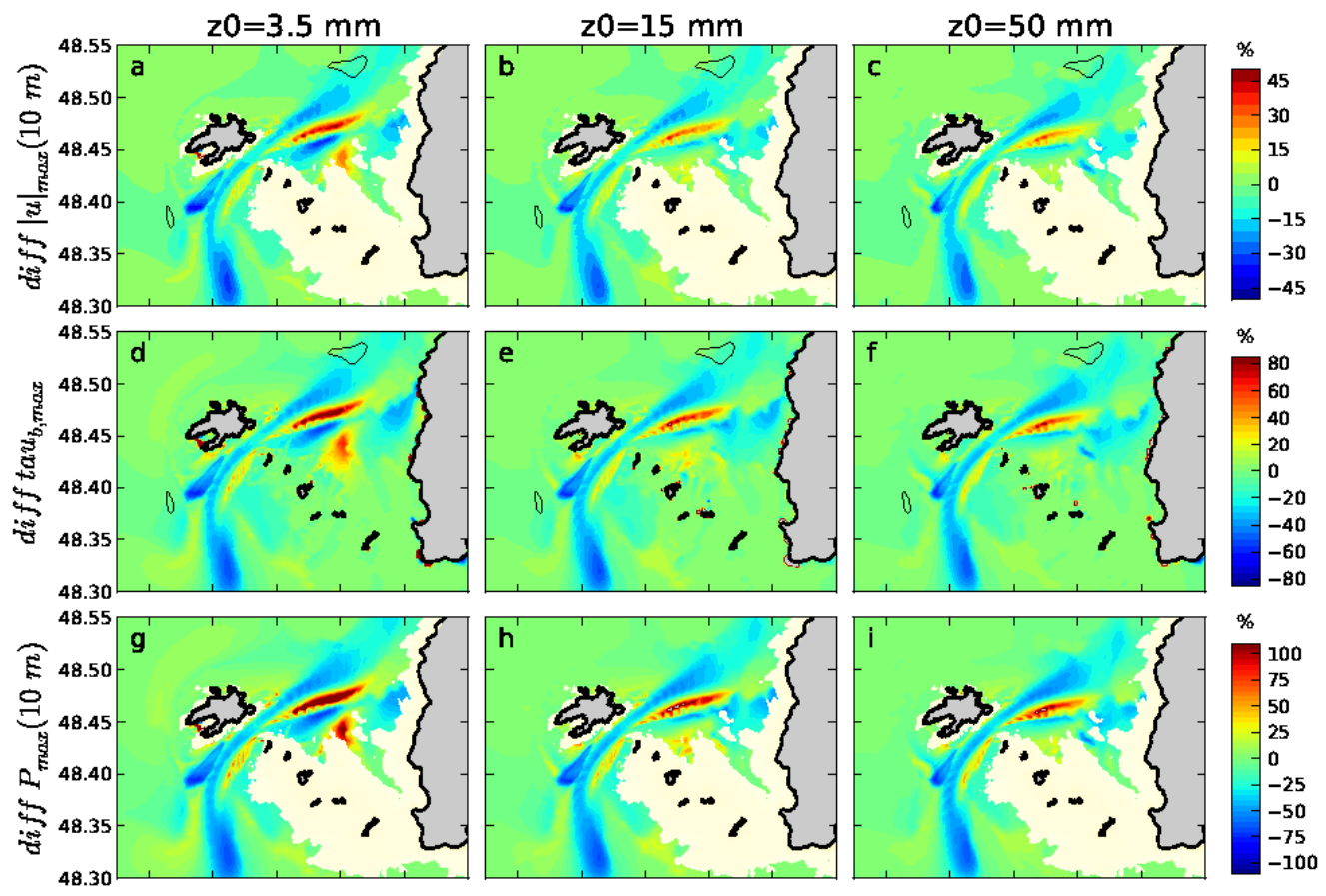

Figure 13: Relative differences, with respect to the configuration without TEC, in predictions of maximum (top) currents $10 \mathrm{~m}$ above the bed, (middle) bottom shear stresses and (bottom) tidal stream powers $10 \mathrm{~m}$ above the bed during a mean spring tidal cycle between configurations integrating and neglecting tidal stream array for three values of the bottom roughness parameter over rock outcrops $\left(z_{0}=3.5,15\right.$ and $\left.50 \mathrm{~mm}\right)$. Predictions $10 \mathrm{~m}$ above the bed are shown for mean water depths over $20 \mathrm{~m}$.

Table 2: Predicted maximum currents at $10 \mathrm{~m}$ above the bed and bottom shear stresses at point \#2 during a mean spring tidal cycle without tidal stream array and associated relative differences with tidal stream array for different values of $z_{0}$ over rock outcrops

\begin{tabular}{ccccc}
\hline $\begin{array}{c}z_{0} \\
(\mathrm{~mm})\end{array}$ & $\begin{array}{c}u_{10, \max }\left(\mathrm{m} \mathrm{s}^{-1}\right) \\
\text { without TEC }\end{array}$ & $\begin{array}{c}\Delta u_{10, \max } \\
\text { with TEC }\end{array}$ & $\begin{array}{c}\tau_{b, \max }\left(\mathrm{N} \mathrm{m}^{-2}\right) \\
\text { without TEC }\end{array}$ & $\begin{array}{c}\Delta \tau_{b, \max } \\
\text { with TEC }\end{array}$ \\
\hline 3.5 & 1.51 & $-8.8 \%$ & 3.67 & $-16.9 \%$ \\
5.0 & 1.46 & $-8.2 \%$ & 3.40 & $-15.8 \%$ \\
10.0 & 1.36 & $-7.2 \%$ & 2.95 & $-13.8 \%$ \\
15.0 & 1.30 & $-6.6 \%$ & 2.72 & $-12.7 \%$ \\
20.0 & 1.27 & $-6.4 \%$ & 2.57 & $-12.3 \%$ \\
30.0 & 1.21 & $-5.7 \%$ & 2.36 & $-11.1 \%$ \\
50.0 & 1.15 & $-4.6 \%$ & 2.11 & $-9.0 \%$ \\
\hline
\end{tabular}




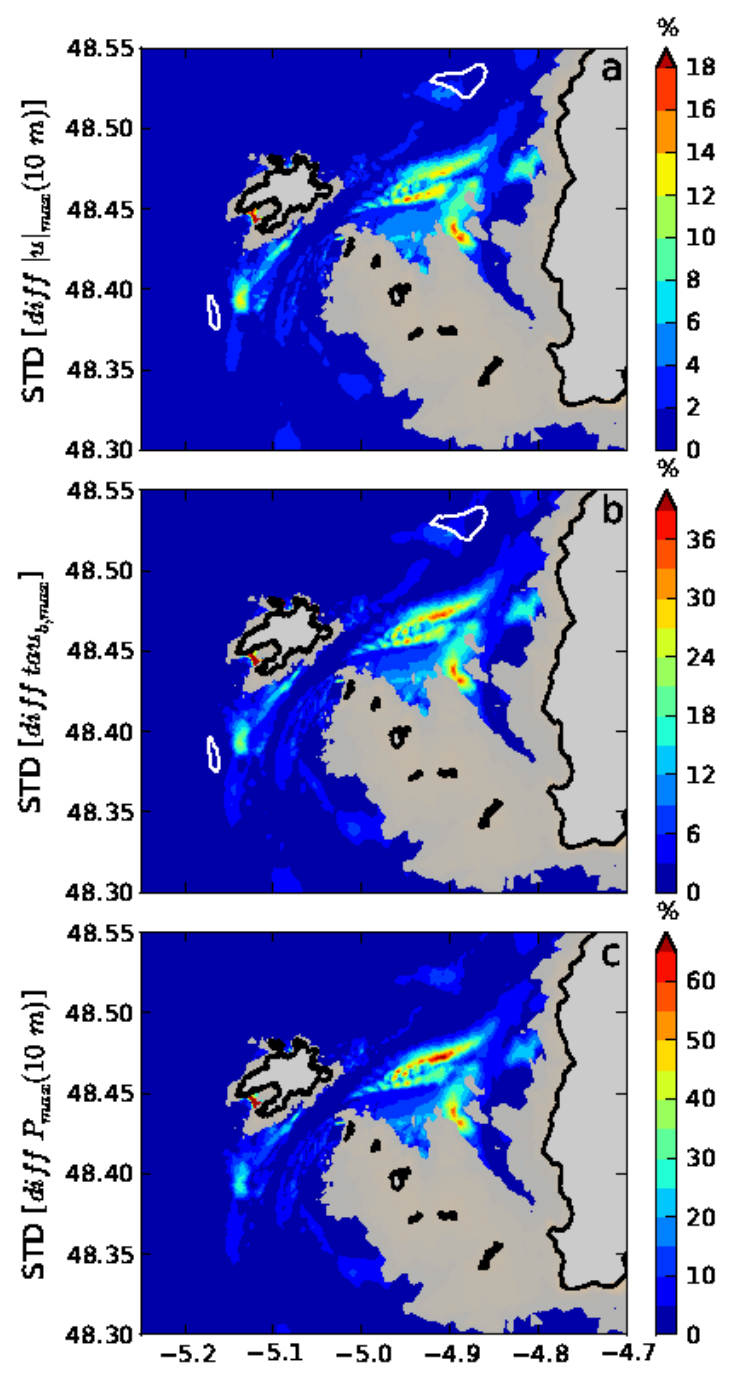

Figure 14: Standard deviations of relative differences displayed in Fig. 13 with respect to the seven values of $z_{0}$ over rock outcrops. 


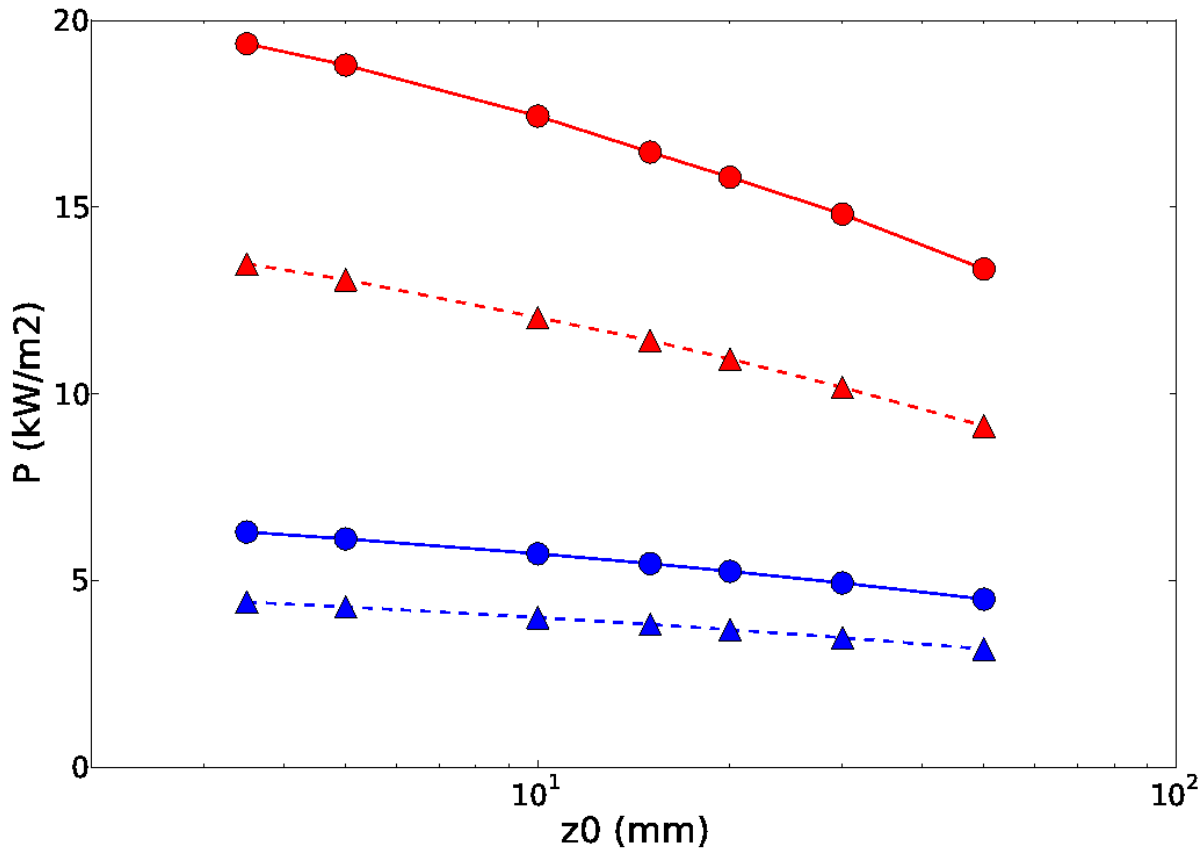

Figure 15: (red) Maximum and (blue) mean stream powers $10 \mathrm{~m}$ above the bed during a mean spring tidal cycle averaged over the area identified for array implementation (continuous line,, 0 ) without and (dotted line, $\boldsymbol{\Lambda}, \mathbf{\Delta}$ ) with tidal stream devices for different values of $z_{0}$ over rock outcrops.

Table 3: Predicted maximum currents at $10 \mathrm{~m}$ above the bed and bottom shear stresses at point \#1 during a mean spring tidal cycle without tidal stream array and associated relative differences with tidal stream array for different values of $z_{0}$ over rock outcrops

\begin{tabular}{ccccc}
\hline $\begin{array}{c}z_{0} \\
(\mathrm{~mm})\end{array}$ & $\begin{array}{c}u_{10, \max }\left(\mathrm{m} \mathrm{s}^{-1}\right) \\
\text { without TEC }\end{array}$ & $\begin{array}{c}\Delta u_{10, \max } \\
\text { with TEC }\end{array}$ & $\begin{array}{c}\tau_{b, \max }\left(\mathrm{N} \mathrm{m}^{-2}\right) \\
\text { without TEC }\end{array}$ & $\begin{array}{c}\Delta \tau_{b, \max } \\
\text { with TEC }\end{array}$ \\
\hline 3.5 & 1.98 & $-2.0 \%$ & 6.24 & $-3.9 \%$ \\
5.0 & 1.94 & $-1.5 \%$ & 6.01 & $-3.0 \%$ \\
10.0 & 1.87 & $-1.4 \%$ & 5.59 & $-2.7 \%$ \\
15.0 & 1.82 & $-1.3 \%$ & 5.33 & $-2.5 \%$ \\
20.0 & 1.78 & $-0.8 \%$ & 5.07 & $-1.5 \%$ \\
30.0 & 1.72 & $-0.7 \%$ & 4.73 & $-1.5 \%$ \\
50.0 & 1.64 & $-1.3 \%$ & 4.32 & $-2.5 \%$ \\
\hline
\end{tabular}


upstream and downstream the tidal farm with flow acceleration on the sides. Induced modifications appear furthermore several kilometres from the array with a prominent extension, up to $15 \mathrm{~km}$, for south-west directed flow. In spite of this asymmetry, more pronounced effects of tidal stream energy extraction are identified in the bank of the Four with a reduction of maximum bottom shear stress, up to $12 \%$, in the reference configuration with $z_{0}=20 \mathrm{~mm}$ over rock outcrops.

3. Spatial distributions of TEC-induced differences show nearly similar spatial patterns with respect to bottom roughness parameterisation of rock outcrops. Main modifications of TEC-induced relative differences appear in the north-eastern and southward edges of the area of interest in relation to decrease and deviation of the flow passing the Strait. Nevertheless, rock roughness parameterisations strongly influence the magnitude of induced differences in the central part of the Strait. Predictions established over the bank of the Four are finally sensitive to $z_{0}$ values of rock outcrops exhibiting different degrees of induced-perturbations on sediment transport.

Whereas the present investigation focuses only on bottom roughness parameterisation of rock outcrops, strong sensitivity of numerical predictions have been exhibited for the predictions without and with tidal stream farm. As numerical predictions are traditionally used by potential TEC developers to optimise devices configurations, such sensitivity study are suggested at the early stages of a tidal farm project. This is naturally a key issue for a refined assessment of tidal stream project, based on Sabella D10 technology, currently planned in the Fromveur Strait. Extended field campaigns may thus be implemented to refine the calibration of bottom roughness promoting observations in areas with the most pronounced sensitivity. Besides the implementation of different configurations of tidal stream array, this numerical analysis will benefit from the development and implementation of a multicomponent sediment transport model integrating the local heterogeneity of available seabed sediments. Another prospective of this research will consist in considering the influences of other forcings such as wind, atmospheric pressure, waves and temperature gradients on the calibration of bottom roughness parameterisation. The associated results will naturally help to remove uncertainties about roughness parameterisation of rock outcrops in areas of interest for tidal stream farm implementation.

\section{Acknowledgements}

The authors are grateful to André Simon (Cerema) for the process of sedimentological data. Current measurements were supplied by the Service Hydrographique et Océanographique de la Marine (SHOM). Simulations were performed on computer facilities CAPARMOR ("CAlcul PARallèle Mutualisé pour l'Océanographie et la Recherche"). The present paper is a contribution to the research programs DIADEMS and FLUSED of the Laboratory of Coastal Engineering and Environment (Cerema, http://www.cerema.fr, http://memphys-lgce.fr.ht).

\section{References}

[1] I. Bryden, D. Macfarlane, The utilisation of short term energy storage with tidal current generation systems, Energy 25 (9) (2000) 893-907. 
[2] I. Bryden, S. Naik, P. Fraenkel, C. Bullen, Matching tidal current plants to local flow conditions, Energy 23 (9) (1998) 699-709.

[3] S. Neill, M. Hashemi, M. Lewis, Optimal phasing of the European tidal stream resource using the greedy algorithm with penalty function, Energy 73 (2014) 997-1006.

[4] P. L. Fraenkel, Marine current turbines: pioneering the development of marine kinetic energy converters, P. Mech. Eng. A-J Pow 221 (2007) 159-169.

[5] S. Neill, E. Litt, S. Couch, A. Davies, The impact of tidal stream turbines on large-scale sediment dynamics, Renewable Energy 34 (2009) 2803-2812.

[6] I. Bryden, S. Couch, Me1-marine energy extraction: tidal resource analysis, Renewable Energy 31 (2006) 133-139.

[7] R. Ahmadian, R. Falconer, B. Bockelmann-Evans, Far-field modelling of the hydro-environmental impact of tidal stream turbines, Renewable Energy 38 (1) (2012) 107-116.

[8] M. Khan, G. Bhuyan, M. Iqbal, J. Quaicoe, Hydrokinetic energy conversion systems and assessment of horizontal and vertical axis turbines for river and tidal applications: a technology status review, Applied Energy 86 (10) (2009) 1823-1835.

[9] S. Neill, J. Jordan, S. Couch, Impact of tidal energy convertor (TEC) arrays on the dynamics of headland sand banks, Renewable Energy 37 (2012) 387-397.

[10] J. Thiébot, P. Bailly du Bois, S. Guillou, Numerical modeling of the effect of tidal stream turbines on the hydrodynamics and the sediment transport - Application to the Alderney Race (Raz Blanchard), France, Renewable Energy 75 (2015) 356-365.

[11] M. Sánchez, R. Carballo, V. Ramos, G. Iglesias, Tidal stream energy impact on the transient and residual flow in an estuary: A 3D analysis, Applied Energy 116 (2014) 167-177.

[12] T. Roc, D. Conley, D. Greaves, Methodology for tidal turbine representation in ocean circulation model, Renewable Energy 51 (2013) 448-464.

[13] S. Kramer, M. Piggott, A correction to the enhanced bottom drag parameterisation of tidal turbines, Renewable Energy 92 (2016) 385-396.

[14] C. Garrett, P. Cummins, The efficiency of a turbine in a tidal channel., Journal of Fluid Mechanics 588 (2007) 243-251

[15] R. Vennell, Tuning tidal turbines in-concert to maximise farm efficiency., Journal of Fluid Mechanics 671 (2011) 587-604.

[16] D. Plew, C. Stevens, Numerical modelling of the effects of turbines on currents in a tidal channel Tory Channel, New Zealand, Renewable Energy 57 (2013) 269-282.

[17] A. Nicolle, M. Karpytchev, Evidence for spatially variable friction from tidal amplification and asymmetry in the Pertuis Breton (France), Continental Shelf Research 27 (2007) 2346-2356.

[18] S. Kumar, R. Balaji, Effect of bottom friction on tidal hydrodynamics along Gulf of Khambhat, India, Estuarine, Coastal and Shelf Science 154 (2015) 129-136.

[19] N. Guillou, G. Chapalain, E. Duvieilbourg, Modelling impact of bottom roughness on sea surface temperature in the Sea of Iroise, Continental Shelf Research 54 (2013) 80-92.

[20] M. Hashemi, S. Neill, P. Robins, A. Davies, M. Lewis, Effect of waves on the tidal energy resource at a planned tidal stream array., Renewable Energy 75 (2015) 626-639.

[21] P. Robins, S. Neill, M. Lewis, S. Ward, Characterising the spatial and temporal variability of the tidal-stream energy resource over the northwest European shelf seas., Applied Energy 147 (2015) $510-522$.

[22] S. Neill, M. Hashemi, M. Lewis, The role of tidal asymmetry in characterizing the tidal energy resource of Orkney, Renewable Energy 68 (2014) 337-350.

[23] M. Lewis, S. Neill, P. Robins, M. Hashemi, Resource assessment for future generations of tidalstream energy arrays, Energy 83 (2015) 403-415.

[24] R. Soulsby, The bottom boundary layer of shelf seas, in: B. E. Johns (Ed.), Physical Oceanography of Coastal and Shelf Seas, Elsevier, Amsterdam, 1983, pp. 189-266.

[25] W. Grant, O. Madsen, Combined wave and current interaction with a rough bottom, Journal of Geophysical Research 84 (C4) (1979) 1797-1808.

[26] SHOM, Courants de marée - Côte Ouest de Bretagne, Technical Report, Service Hydrographique et Océanographique de la Marine (1994)

[27] M. Thiébaut, A. Sentchev, Estimation of tidal stream potential in the Iroise Sea from velocity observations by high frequency radars, Energy Procedia 76 (2015) 17 - 26, European Geosciences Union General Assembly 2015 - Division Energy, Resources and Environment, EGU 2015.

[28] A. Hamdi, French marine landscapes maps, Technical report, Ifremer (2007).

[29] F. Hinschberger, A. Guilcher, M. Pruleau, A. Moign, Y. Moign, Carte sédimentologique sous-marine des côtes de France. Feuille de Brest. Echelle 1/100000., Tech. rep., DGRST-CNEXO (1968). 
[30] A. Hamdi, M. Vasquez, J. Populus, Cartographie des habitats physiques Eunis - Côtes de France, Technical Report DYNECO/AG/10-26/JP, Ifremer (2010).

[31] J. Hervouet, Hydrodynamics of free surface flows, modelling with the finite element method, Cambridge University Press, Cambridge, 2007.

[32] R. Soulsby, Dynamics of marine sands, H.R. Wallingford, 1997.

[33] Z. Defne, K. Haas, H. Fritz, Numerical modeling of tidal currents and the effects of power extraction on estuarine hydrodynamics along the Georgia coast, USA, Renewable Energy 36 (2011) 3461-3471.

[34] P. Work, K. Haas, Z. Defne, T. Gay, Tidal stream energy site assessment via three-dimensional model and measurements, Applied Energy 102 (2003) 510-519.

[35] N. Guillou, G. Chapalain, Numerical modelling of nearshore wave energy resource in the Sea of Iroise, Renewable Energy 83 (2015) 942-953.

[36] N. Guillou, G. Chapalain, Wave energy potential in the Sea of Iroise, in: 11th European Wave and Tidal Energy Conference Series, Nantes, France, 2015.

[37] B. Loubrieu, J. Bourillet, E. Moussat, Bathy-morphologique régionale du Golfe de Gascogne et de la Manche, modèle numérique, Tech. rep., Ifremer (2008).

[38] L. Louvart, C. Grateau, The Litto3D project, in: Oceans 2005 - Europe, Brest, France, 2005.

[39] H. Muller, F. Dumas, B. Blanke, V. Mariette, High-resolution atmospheric forcing for regional oceanic model: the Iroise Sea, Ocean Dynamics 57 (4-5) (2007) 375-400.

[40] N. Guillou, G. Chapalain, E. Duvieilbourg, Sea surface temperature modelling in the Sea of Iroise: assessment of boundary conditions, Ocean Dynamics 63 (2013) 849-863.

[41] G. Egbert, A. Bennett, M. Foreman, TOPEX/POSEIDON tides estimated using a global inverse model, Journal of Geophysical Research 99 (1994) 24821-24852.

[42] C. Willmott, On the validation of models, Physical Geography 2 (2) (1981) 219-232.

[43] SHOM, http://datashom.fr (2016)

[44] V. Ramos, R. Carballo, M. Alvarez, M. Sánchez, G. Iglesias, Assessment of the impacts of tidal stream energy through high-resolution numerical modelling, Energy 61 (2013) 541-554.

[45] L. Myers, A. Bahaj, An experimental investigation simulating flow effects in first generation marine current energy converter arrays, Renewable Energy 37 (2012) 28-36.

[46] R. Ahmadian, R. Falconer, Assessment of array shape of tidal stream turbines on hydroenvironmental impacts and power output, Renewable Energy 44 (2012) 318-327. 